\title{
Fog at Abu Dhabi International Airport
}

\author{
M. P. de Villiers ${ }^{1}$ and J. van Heerden ${ }^{2}$
}

${ }^{1}$ Weather Services International, Birmingham, UK

2University of Pretoria, Department of Geography, Geoinformatics and Meteorology, Pretoria, South Africa

${ }^{*}$ Correspondence to: Michael de Villiers, Weather Services International, 22-24 Vittoria Street, Birmingham, B1 3PE, UK Email: michaeld@wsieurope.com

Fog that reduces visibility to the point where aircraft have to divert to another airport is not uncommon at Abu Dhabi International Airport (ADIA) in the United Arab Emirates (UAE) (Figure 1). Over the period 1982 to 2003, the average annual frequency of fog at ADIA was 38 nights a year, the highest being 56 in 2000 and the lowest 23 in 1992. Fog is defined as occurring when water vapour in the atmosphere condenses into minute water droplets and the horizontal visibility falls below $1000 \mathrm{~m}$ (UK Meteorological Office (UKMO), 1991).

The airport is equipped with a CAT3A Instrument Landing System (Abu Dhabi Department of Civil Aviation, 2006). This means that not all fog events result in diversions. Aircraft can still land with a minimum runway visual range (RVR) of $200 \mathrm{~m}$ and $0 \mathrm{~m}$ decision height, or, put another way, $0 \mathrm{~m}$ cloud base or vertical visibility, provided the pilots are currently qualified and the aircraft is suitably equipped. RVR is the greatest distance that runway lights can be seen in the direction of landing, or take-off, along the runway as seen from the centre-line at the point of touchdown at the average eyelevel of the pilot (UKMO, 1994). At ADIA it is electronically measured by equipment alongside the touchdown point at each end of the runway with another sensor at the centre point. This distance is usually further than the minimum non-directional distance that can be observed with the naked eye.

Diverting flights to another airport results in considerable cost to airlines. The extra expense includes fuel used and hotel accommodation for the passengers. Flight and cabin crew can become duty time expired and by law may not fly again until they have had a specific period of time off

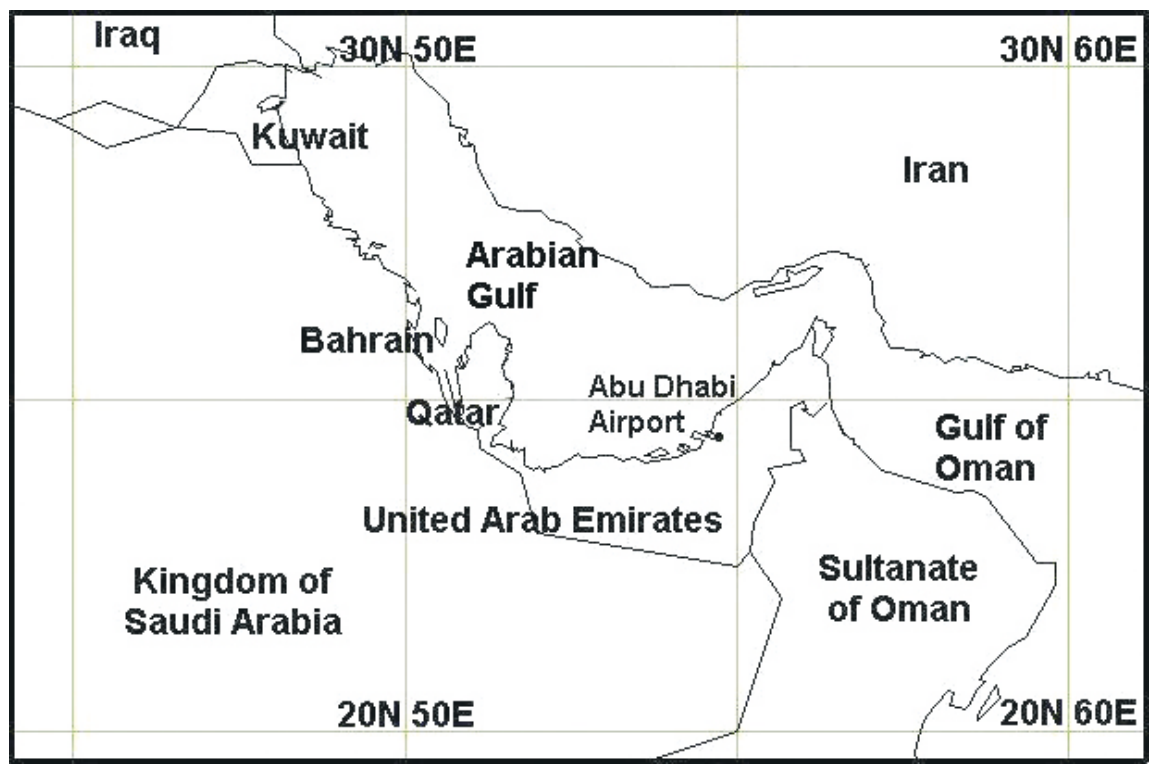

Figure 1. Abu Dhabi International Airport's position in the UAE relative to the Arabian Gulf and the Middle East.

duty. Furthermore, passengers still have to get to their desired destinations. When inclement weather is forecast, flight crews, for their own peace of mind, are inclined to load more fuel than the legal minimum required. This results in extra weight and therefore extra fuel consumption and lower profit for the flight. If cargo carried has to be decreased as a result, this will further decrease profit.

Many flights to ADIA originate from places up to ten hours' flight time away. Added to this the flight dispatcher does the flight planning at least an hour before departure time. As will be seen later, fog is most common about 0300 to 0900 local time (LT) (2300 to 0500 UTC). So the best possible forecast and fog warning need to be available by 1600 to $1800 \mathrm{~h}$. The latest available 24-hour terminal area forecast (TAF) would be the 1200 to 1200 UTC TAF, which is issued 6 hours before the valid time at $1000 \mathrm{~h}$ or possibly the 1800 to 1800 UTC TAF issued by $1600 \mathrm{~h}$. This means that the latest available forecast could be 23 or more hours old before the aircraft is due to land, or, at best, at least 11 hours old for the later TAF.
Aircraft such as the Airbus A340-500 have an endurance of up to 19 hours with Singapore Airlines making 18-hour non-stop flights between Singapore and New York (Airbus Industrie, 2006). So it is possible that, in the future, the present lead-time for forecasts issued at ADIA will be even longer.

Improved knowledge of the circumstances when fog occurs, or does not occur, will result in more accurate fog forecasts, fewer false alarms and earlier warning of the onset of fog. This will in turn result in improved flight planning by the airlines operating in and out of the airport, increased profit and improved preparedness on the part of the relevant airport authorities.

During the 22 years from 1982 to 2003, 551 fog events at ADIA were analysed using surface observations at ADIA. For 2002 to 2003, 31 fog events were analysed in detail, including 56 atmospheric soundings on most afternoons prior to the fog and the early morning in question. During the two years of 2002 and 2003, 20 events, when fog was not expected and did not occur, were also analysed for comparative purposes. 


\section{Fog-producing processes}

Most fog forms as a result of cooling of the air in contact with the Earth's surface. The two primary types of fog are advection fog (due to warmer air streaming over a colder surface) and nocturnal radiation fog (ground heat loss due to outgoing radiation). Other fog types are upslope, frontal and steaming fog (UKMO, 1997). The mixing of two slightly unsaturated air parcels, initially at different temperatures, is also important (Roach, 1994). Fog is rarely produced by a single process, but rather by any combination of the above, although one of them may be dominant.

Nocturnal radiation fog is most likely when surface winds are calm, or light, with a clear sky (or limited to thin, high cloud) and dry air above a moist boundary layer of about $100 \mathrm{~m}$ and a weak pressure gradient. Anticyclones are usually associated with the correct ingredients for the formation of radiation fog and are rarely associated with a cyclonic circulation. Dry air aloft in subsiding conditions promotes surface radiation cooling while suppressing the surface wind. A clear sky allows much more heat to escape, thereby enhancing radiation cooling. A light wind enables the correct amount of turbulent mixing to take place so not all condensation is in the form of dew, but condensation also takes place in the air (Taylor, 1917; Ricks, 1981; UKMO, 1994, 1997). It has been noted that initial fog formation occurs when the wind at $2 \mathrm{~m}$ above the ground temporarily drops to $1 \mathrm{kn}$ or less (Findlater, 1985).

Due to dry desert conditions next to the warm Gulf, fog formation in the UAE is usually a combination of advection and nocturnal radiation processes. Warm and moist Arabian Gulf air is carried inland by the afternoon sea breeze and radiation cooling from the desert surface does the rest. Apart from the Hajar Mountains in the extreme east, most of the UAE is below $300 \mathrm{~m}$ above mean sea level (AMSL). ADIA is on a coastal plain that does not exceed $40 \mathrm{~m}$ AMSL (UAE Ministry of Communications, 1996; Abu Dhabi Explorer, 2001). So upslope fog is not an important form of fog production. Due to its tropical position frontal fog is also, at most, a rare occurrence. The same applies to steaming fog.

\section{Analysis of fog frequency}

Local rules of thumb for forecasting fog at ADIA abound. These include the following: relative humidity must be greater than $80 \%$ at $2200 \mathrm{~h}$ for fog to form later in the night; fog always occurs two nights in a row; fog does not form when certain wind directions occur; and fog does not occur during a full moon. Another is that very hazy conditions during the afternoon are often a precursor to fog later in the night, especially if low stratus cloud comes off the sea and passes inland of the airport. The logic is that hazy conditions confirm the abundance of hygroscopic particles favourable for condensation. Some rules of thumb can be shown to be statistically valid, others logically valid (as above) and others difficult to prove.

With respect to greater than $80 \%$ surface relative humidity at $2200 \mathrm{~h}$ being an indicator of fog, an analysis of all fog events during the three years from 2000 to 2002 was made. It was found that $90 \%$ of fog events occurred when the relative humidity was greater than $73 \%$ at this time (Figure 2). Investigation of nights when fog did not occur showed that the relative humidity often exceeded $80 \%$ at this time as well. This was especially so during the hot and humid summer nights. Figure 2 shows the $90 \%$ and higher probability for other times in the night and late afternoon. The minimum relative humidity at a specific hour during a fog night is also shown. The conclusion is that this method can only be used as a short lead-time Nowcast tool.

During the ten-year period from 1993 to 2002 it was found that there was an $18 \%$ chance that fog will occur on two consecutive days, $6 \%$ that it will occur three days in a row, $2 \%$ and $1 \%$ for four and five days in succession, respectively. That is, persistence forecasting is most unlikely to be successful.

The highest frequency of fog occurs in the autumn months of September and October and far exceeds the number of fog days at the end of winter and spring (Figure 3 ). Ideally a minimum of 30 years' data is needed to determine the climate of a place, but the airport has only been at its present location since 1982. Therefore, the figures may not be entirely representative. The sinusoidal wave, with a primary maximum in autumn, has also been distorted by some exceptionally extreme fog months, such as 17 days in October 1991, 16 days in December 1998 and 12 days in January 1985.

As can be expected with longer nights in winter, fog occurs during more hours of the night and more frequently than in summer. During the winter months of January and February 1993 to 2002 (ten years) fog occurred between 2200 and $1100 \mathrm{~h}$ and most frequently between 0200 and $0900 \mathrm{~h}$ (Figure 4). In summer (July and August) fog occurred between 0200 and $0800 \mathrm{~h}$ and most of it between 0400 and $0700 \mathrm{~h}$. These two summer months and two winter months were selected because they are the two hottest and two coldest months respectively.

When the fog forms, the visibility quickly and most often deteriorates to a value less than the CAT3A $200 \mathrm{~m}$ minimum (Figure 5). This occurred on $54 \%$ of the 1166 fog hours in the ten-year period 1993 to 2002 , or $58 \%$ out of a total of 104 fog hours if one considers the visually observed CAT1 $800 \mathrm{~m}$ limit. This deterioration is particularly apparent between the hours of 0200 and 0900

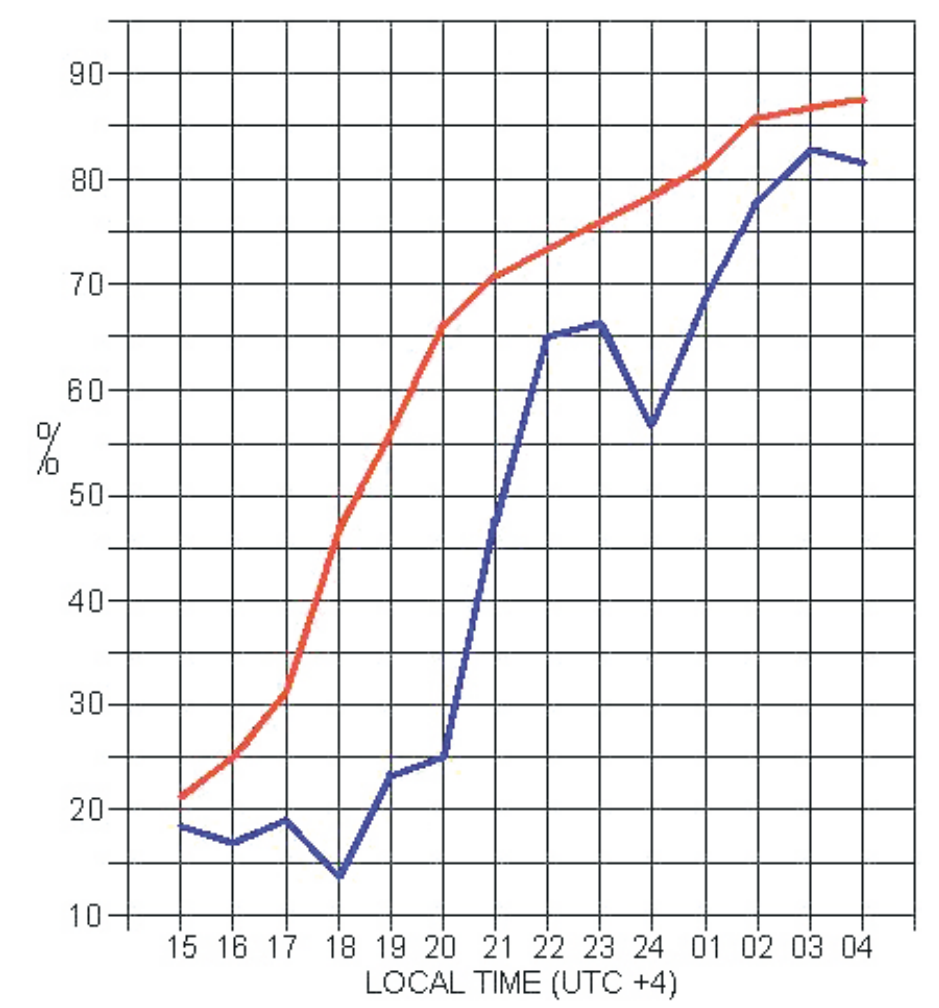

Figure 2. Surface humidity fog risk. The risk of fog later in the night is $\geq 90 \%$ if the relative humidity at a given time equals, or exceeds, the red-line value. The blue line indicates the minimum value when fog has formed later in the night. 


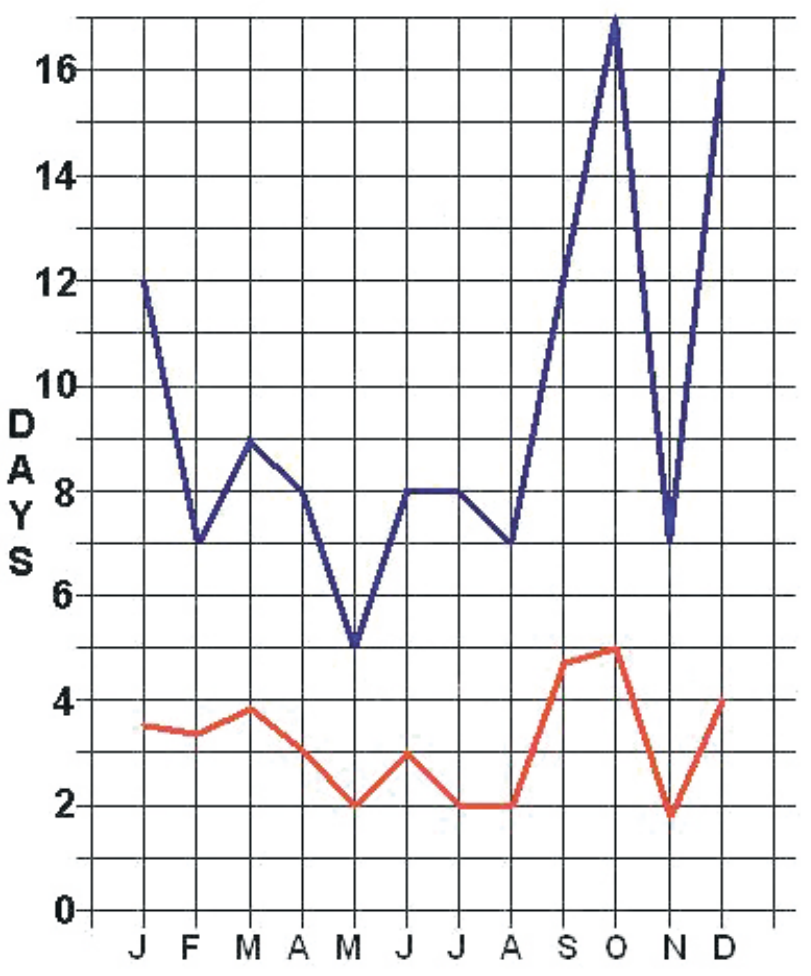

Figure 3. The extreme highest number of days with fog per month (blue line) and mean number of days with fog per month (red line).

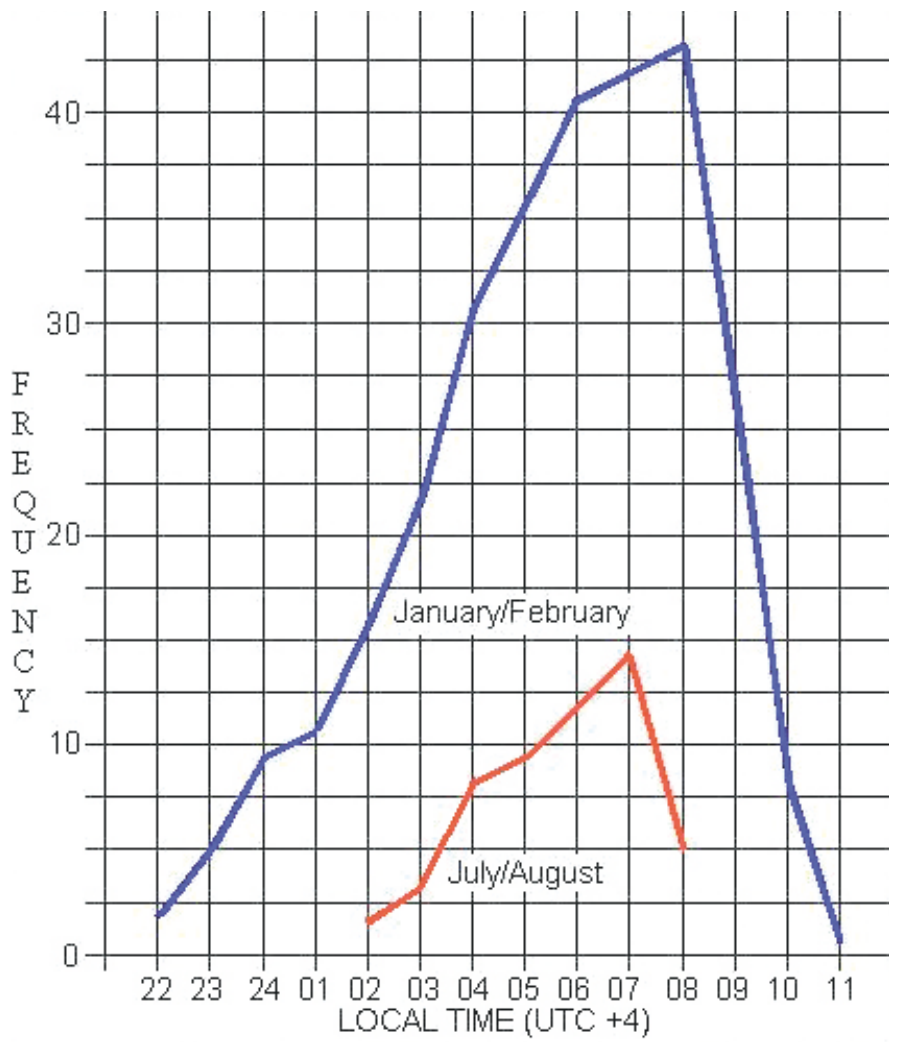

Figure 4. The hourly frequency of fog (visibility $<1000 \mathrm{~m}$ ) in winter (blue line) and summer (red line) for the period 1993-2002. The frequency is higher in winter and begins earlier in the evening and ends later in the morning than in summer.
(Figure 5). Taken into consideration with the graphs in Figure 4, this is a bigger problem in winter than in summer.

Local lore, with respect to wind change, is that fog forms when the north-westerly wind during the day changes through easterly to south-easterly overnight, becoming light or calm in the process. Furthermore, fog is likely to occur after Shamal has been blowing for a few days and then drops. A Shamal is defined as a northwesterly, or northerly, wind with the hourly mean wind speed at, or greater than, $17 \mathrm{kn}$ for at least three hours in a day (Rao et al., 2001). On the other hand, if the wind backs from north-westerly to a light south-westerly, or southerly desert track and perhaps south-easterly later, fog does not occur. A study of overnight hourly observed wind changes during fog events from 2000 to 2003 revealed that the local belief is generally true. Fog occurred $87 \%$ of the time when the wind veered through easterly, with the wind backing through westerly during the remaining $13 \%$. The propensity for the wind to veer rather than back is to be expected given the fact that the Coriolis effect deflects the wind to the right in the Northern Hemisphere (Bradbury, 1989; UKMO, 1994). Note, there were no fog events when the wind persisted off the desert from a southerly direction throughout the night.

The wind generally becomes lighter at night, especially in fog events. Inspection of hourly wind observations on 20 nights when fog was expected and did not occur revealed that most often the surface wind blew consistently at about 3-6 kn and sometimes higher, irrespective of whether it veered or backed. On one occasion when fog did occur, the wind veered from northwesterly to easterly and persisted blowing at $5 \mathrm{kn}$.

Fog did not occur when the wind persisted from the north-west to north-east. This is most likely during a Shamal when there is an increased pressure gradient between a surface low-pressure cell or trough to the north-east, or east, and a ridge of high pressure over northern Saudi Arabia (Membery, 1983). Under these conditions the wind is more likely to back to southwesterly over the Emirates at night due to the land breeze effect. On rare occasions fog did occur when the wind backed through westerly (13\%). However, when a Shamal drops, fog is likely. This was the case when Abu Dhabi had been subjected to days of persistent moderate to fresh summer northwesterly Shamal winds over the Arabian Gulf with a low-pressure cell over southern Iran and then experienced four nights of fog from 18 July 2002 when it was now under a Col with a weak pressure gradient of about $1 \mathrm{hPa}$. A similar situation is presented in the following winter event. 


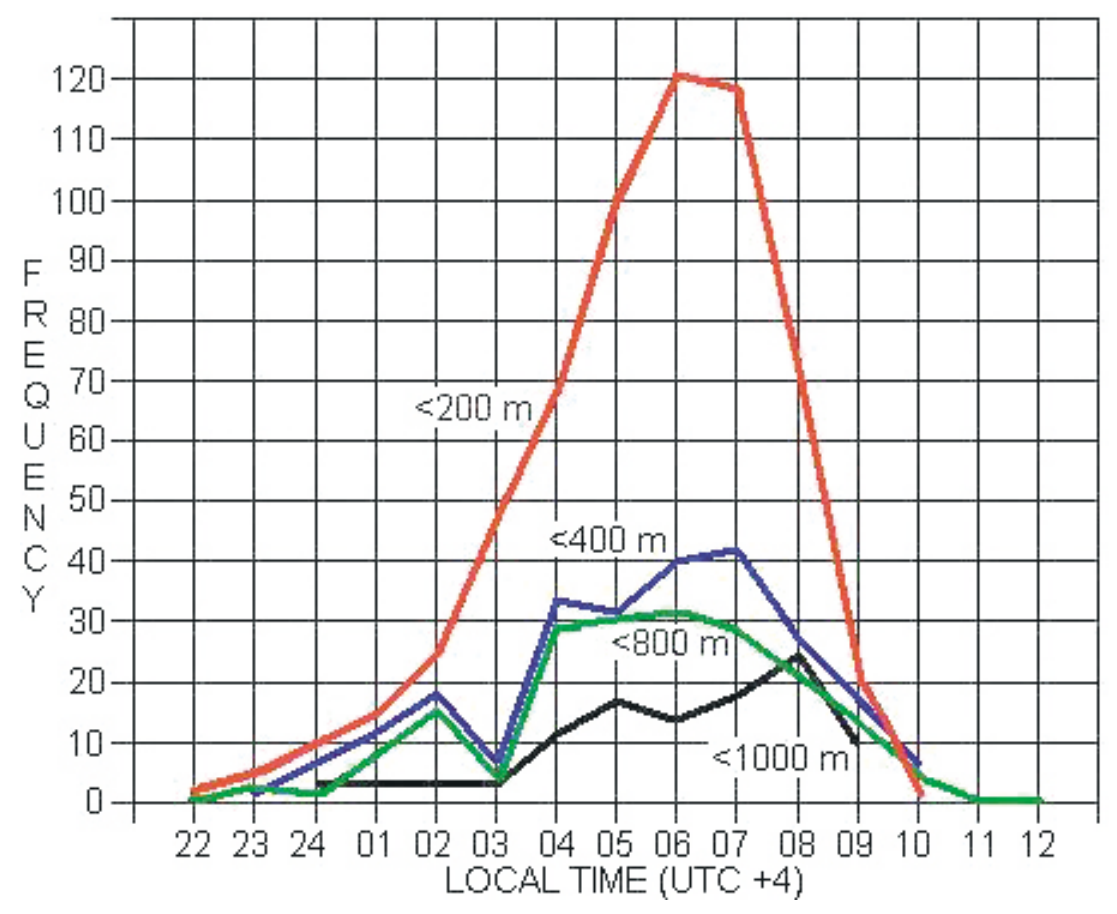

Figure 5. The hourly frequency of fog below different visibility levels for the period 1993-2002. 0600$0700 \mathrm{~h}$ are most often the times of the worst visibility.

\section{A winter example, 8-11 January 2001}

The fog occurred after three days of northwesterly Shamal winds. These were fresh to strong at first but by the time the fog occurred the winds had moderated considerably as an anticyclone moved overhead and the winds became light at the surface and aloft in the boundary layer up to $1000 \mathrm{~m}$.

Each afternoon prior to the fog a $5-10 \mathrm{kn}$ north-westerly sea breeze began between 1600 and $1800 \mathrm{~h}$ (Figure 6). Typically, the wind later became light and veered to the east and then south-east. Fog formed once the $10 \mathrm{~m}$ wind had become almost calm, the exception being the morning of 10 January when it formed with an easterly wind of $5 \mathrm{kn}$.

As is to be expected in winter, the fog formed earlier in the night than is usual in summer and finished later, the fog forming between 0100 and $0200 \mathrm{~h}$ and finishing at about 0900 to $1000 \mathrm{~h}$ (Figure 6). Notice how the visibility quickly fell to less than $200 \mathrm{~m}$ (with no discernable cloud base) and just as rapidly improved afterward.

It was noted that the fog formed when the air temperature fell to below the maximum dew-point temperature experienced the previous afternoon or earlier in the evening. This critical temperature was a feature of all the fog events analysed between 2001 and 2003. In this case fog formed after about 2 hours and was about $1.5 \mathrm{deg} C$ lower (Figure 6), although sometimes fog formed 3-6 hours after the air temperature fell below the critical temperature. the wind is going to drop sufficiently for fog to form and then a nail-biting night wondering whether the correct decision has been made.

\section{Surface low pressure to the west and anticyclone over southern Iran}

If the low pressure is anywhere from the immediate north-west to the south of the UAE (with, by implication, an anticyclone over southern Iran), it causes a dry southerly to south-easterly wind to blow off the desert. In extreme conditions the wind will be strong enough to cause a dust storm.

On 13 June 2003, the 0300 UTC $(0700 \mathrm{~h})$ United States National Weather Service (NWS) Global Forecast Service (GFS) model indicated a south-easterly wind of $5 \mathrm{kn}$ at $10 \mathrm{~m}$ to the east of a low pressure and $10 \mathrm{kn}$ at $950 \mathrm{hPa}$ (Figure 7), which should have been strong and deep enough to keep surface moisture at the airport low enough to prevent fog formation. Surface observations show that there was a marked increase in the dew-point temperature with the northwesterly sea breeze in the afternoon (Figure 8). However, even though the surface wind became light the air remained sufficiently dry to prevent fog forming, before the wind picked up off the desert. It is worth noting that the air temperature never dropped as low as the maximum dew-point temperature earlier in the day. The pre-dawn 0000 UTC $(0400 \mathrm{~h})$ atmospheric sounding confirmed that a dry offshore easterly wind of $3-5 \mathrm{kn}$ blew from ground level up to a temperature inversion at $292 \mathrm{~m}$ above MSL with the humidity below 50\% near the

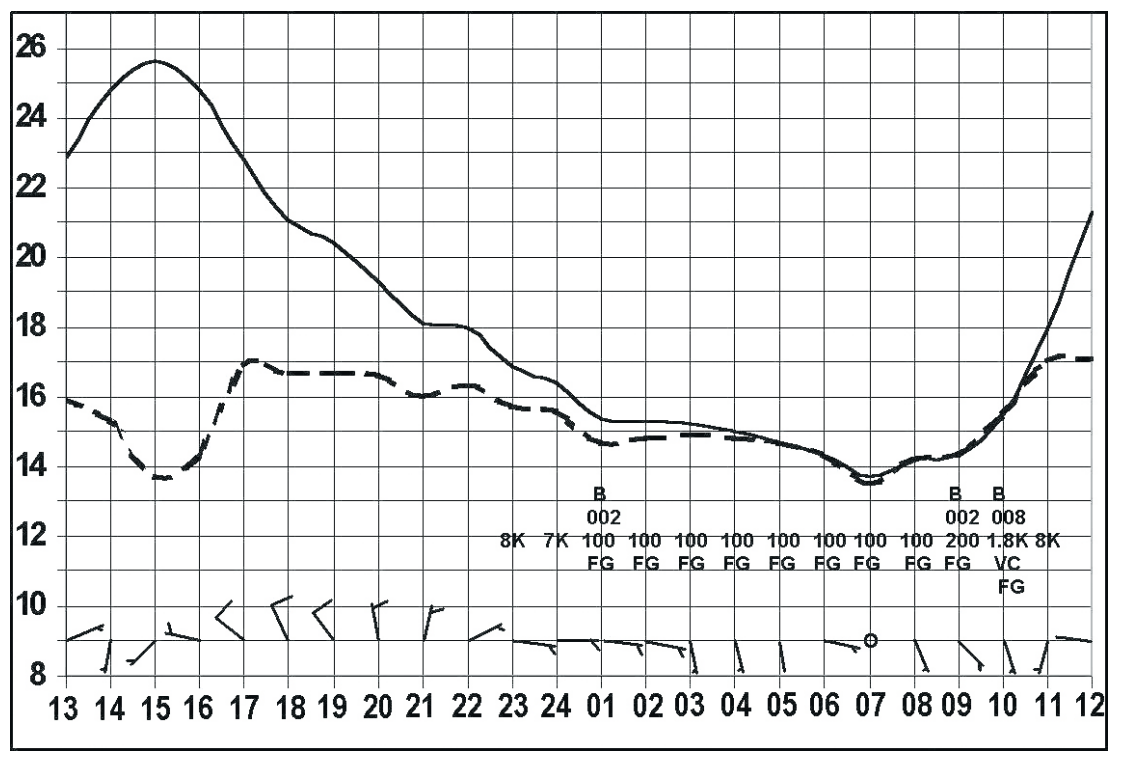

Figure 6. Surface observations on 9 and 10 January 2003 local time. Continuous line - dry bulb air temperature, dashed line - dew-point temperature; B indicates broken 5-7 oktas of cloud; 002 and 008 indicate 200 and 800 feet AGL. Visibility is in kilometres (K) and hundreds of metres. FG indicates fog and VCFG means fog in vicinity. Wind arrows indicate the direction and speed in $5 \mathrm{kn}$ increments. 
surface and $15 \%$ at $227 \mathrm{~m}$. The end result was no fog with the visibility, aggravated by the low sun angle, being reduced to $8000 \mathrm{~m}$ in dawn haze.

\section{Surface low pressure to the east}

If the low pressure is to the south-east and the north-east, the situation is more complicated, because the northerly wind is naturally onshore and brings moist air from the sea to the land. The example below also highlights the dilemma facing the forecaster, of whether or not to believe model data.

According to the wind circulation on 31 August 2003, the GFS prognosis expected a low-pressure cell to be to the south-east of ADIA at 0300 UTC. It also indicated above $95 \%$ surface relative humidity inland, brought by a light onshore northerly to north-easterly wind. Even the prognostic $0400 \mathrm{~h}$ atmospheric profile was ominous with a low surface temperature inversion. The only reassuring aspect was the moderate strength winds at $950 \mathrm{hPa}$ and $900 \mathrm{hPa}$. The problem for the forecaster is, will the wind remain onshore and strong enough to prevent fog irrespective of the high surface relative humidity, or will it drop, turn to light offshore and fog form?

The surface observations (Figure 9) show that once again there was a moderate afternoon sea breeze. The wind did become light during the night and, contrary to the model prognosis, veered to easterly and a light southerly land breeze during the early hours. However, while the air cooled to a minimum temperature fractionally below the afternoon maximum dew-point temperature, the dew-point depression was such that there was never enough surface moisture for saturation. The worst visibility experienced was $6000 \mathrm{~m}$ in dawn haze.

The explanation for the fog not forming lies in turbulent mixing of the air (Brown and Roach, 1976; Roach et al., 1976; UKMO, 1997). At the surface the wind blew at 3-6 kn throughout the night and the relative humidity never exceeded $86 \%$. Above the ground, according to the $0400 \mathrm{~h}$ sounding, the wind increased with height, changing from north-easterly $6 \mathrm{kn}$ to northerly $8 \mathrm{kn}$ through a weak temperature inversion at $183 \mathrm{~m}$ above MSL to the main temperature inversion at $759 \mathrm{~m}$ above MSL, while the relative humidity below the main inversion varied from $70 \%$ to $86 \%$.

\section{Conclusions}

Fog occurs often enough throughout the year at ADIA to be a continual source of concern, although the highest frequency is during the autumn and early winter months and the least in summer. It forms earlier in the night in winter and lasts longer than in

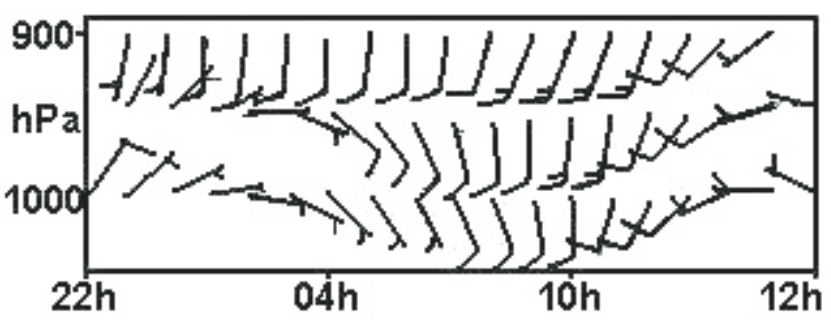

Figure 7. 12/13 June 2003 overnight vertical time series of the wind velocity as predicted by the GFS model. Winds are from the surface to $900 \mathrm{hPa}$ (about $300 \mathrm{~m}$ ).

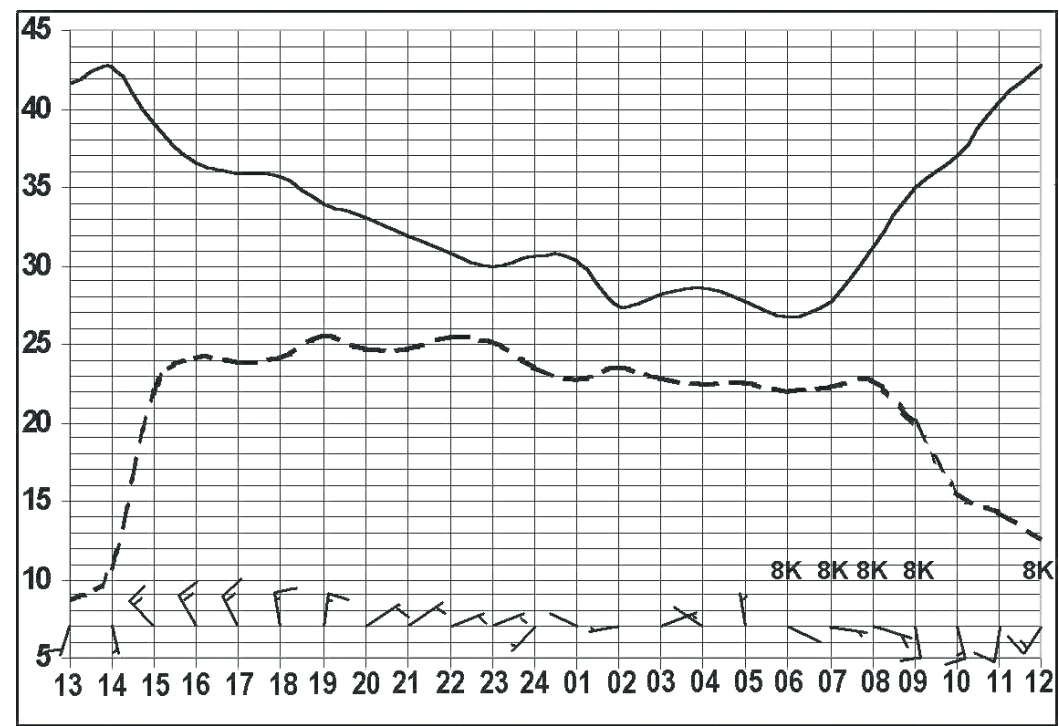

Figure 8. Surface observations on 12 and 13 June 2003. Elements as in Figure 6.

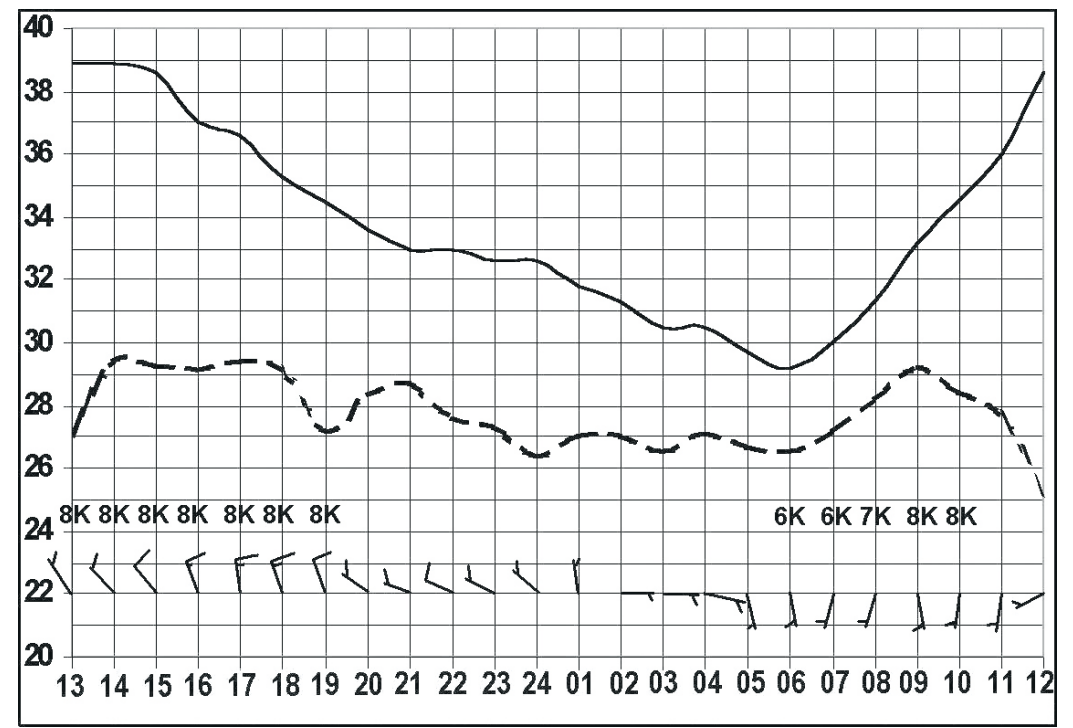

Figure 9. Surface observations on 30 and 31 August 2003. Elements as in Figure 6. 
summer. Most of the occurrences are between 0100 and $1000 \mathrm{~h}$ in winter and 0400 to $0700 \mathrm{~h}$ in summer. More often than not the fog clears within about two hours after sunrise.

In accord with local belief, fog is most likely when a north-westerly sea breeze, or Shamal wind, carries moisture inland and the wind then dies away and veers through easterly to light south-easterly during the night. It rarely occurs when the wind backs through westerly. Fog does not occur when the surface wind blows onshore through the night, such as in a persistent Shamal, or when it persists from the south off the desert.

Contrary to local lore, there is little risk of fog on two or more consecutive nights. So persistence forecasting is unlikely to be successful and consideration must be given to changing circumstances. As a rule the chance of fog later in the night is high if the forecast morning minimum screen air temperature is expected to be lower than the maximum dew-point temperature during the previous afternoon, or early evening, as long as drier air does not arrive during the night.

Very hazy conditions or low stratus cloud, in the afternoon, or evening, are useful visual indicators of fog later, but are not infallible.

Fog does not occur when a surface lowpressure cell is situated to the west of the UAE. This pressure pattern produces a dry offshore southerly flow that strengthens the early morning land breeze. The stronger and earlier beginning of the land breeze mixes dry desert air with the moist sea air and prevents fog formation. A similar result is achieved when an anticyclone is over southern Iran.

Model data are of great value in that they indicate synoptic conditions, boundary layer winds and relative humidity. However, they can be misleading at times, such as indicating too high surface humidity, or incorrect wind velocity.

\section{Acknowledgements}

Thanks are due to the Meteorological Office, Abu Dhabi International Airport, Abu Dhabi Directorate for Civil Aviation, United Arab Emirates for the observation data, the South African Weather Service library and for the support of Weather Services International.

\section{References}

Abu Dhabi Department of Civil

Aviation. 2006. http://www.

dcaauh.gov.ae/english/abudhabi/fact_file. htm. Accessed 16 February 2006

Abu Dhabi Explorer. 2001. 2nd edition. Explorer Publishing: Dubai.

Airbus Industrie. 2006. http://www. airbus.com/en/aircraftfamilies/a330a340/ a340-500/. Accessed 16 February 2006.

Bradbury T. 1989. Meteorology and Flight. $A$ and C Black: London.

Brown R, Roach WT. 1976. The physics of radiation fog: II - A numerical study. Q. J. Roy. Meteorol. Soc. 102: 335-354.

Findlater J. 1985. Field investigations of radiation fog formation at outstations. Meteorol. Mag. 114: 187-201.

Membery DA. 1983. Low level wind profiles during the Gulf Shamal. Weather 38: 18-24.
Rao PG, Al-Sulaiti M, Al-Mulla AH. 2001. Winter Shamals in Quatar, Arabian Gulf. Weather 56: 444-451.

Ricks EL. 1981. Some empirical rules for forecasting fog and Stratus over northern Florida, southern Georgia and adjacent coastal waters. NOAA Technical Memorandum NWS SR-104. National Hurricane Center, Miami, Florida. August.

Roach WT. 1994. Back to basics: Fog: Part 1 - Definitions and basic physics. Weather 49: 411-415.

Roach WT, Brown R, Caughey SJ, Garland BA, Readings CJ. 1976. The physics of radiation fog: I - A field study. Q. J. Roy. Meteorol. Soc. 102: 313-334.

Taylor GI. 1917. The formation of fog and mist. Q. J. Roy. Meteorol. Soc. 43: 241-268.

UAE Ministry of Communications. 1996. UAE Climate. Cultural Foundation Publications.

UK Meteorological Office (UKMO). 1991. Meteorological Glossary, 6th edition. HMSO: London.

UK Meteorological Office (UKMO). 1994. Handbook of Aviation Meteorology. HMSO: London.

UK Meteorological Office (UKMO). 1997. Source book to the forecasters' reference book. Met.O.1024, Meteorological Office College.

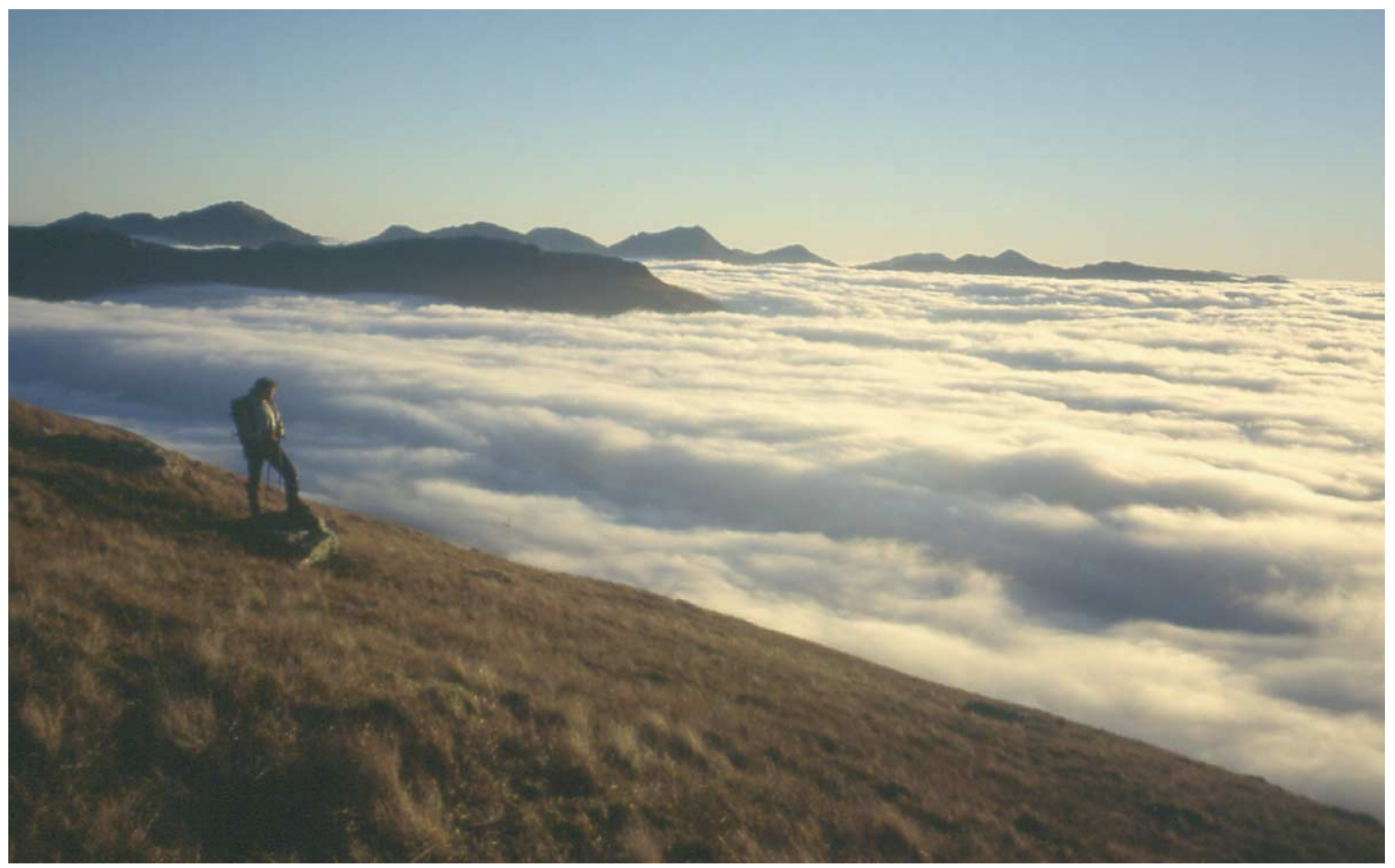

Mountains of the Arrochar Alps stick out above a blanket of fog as seen near sunset from the slopes of Ben Lui, southern highlands, Scotland, in November 2005. The fog lay below an altitude of approximately 500 metres and persisted all day in a gentle southwesterly breeze. (৫ EJ Kennett.) 